\title{
Introduction to A Research Agenda for Entrepreneurship Policy: why we need a different research agenda on entrepreneurship policy
}

David Smallbone and Friederike Welter

This chapter discusses why we need a changed research agenda on entrepreneurship policy. In recent years there has been a remarkable growth of interest in entrepreneurship and small and medium-sized enterprise (SME) development from policy makers, practitioners and academics. From a public policy perspective, entrepreneurship is seen as one of the driving forces behind a modern economy. That being the case, not surprisingly, policy makers and politicians have jumped on the bandwagon to take full advantage of this phenomenon. The widespread nature of entrepreneurship policy means that a review of where policy has reached will assist us in identifying an agenda for change.

\section{Defining key terms}

First of all, the terms 'SME', 'entrepreneurship' and 'public policy' need some definition. Entrepreneurship policy has, in practice, grown out of SME policy but with a different emphasis. Whereas SME policy is based on offering support to businesses that meet the size definition of SME, entrepreneurship policy is more sharply focused on those people starting a new business or projects within an existing business. Though some commentators use the term SME and entrepreneurship interchangeably, the two terms refer to rather different policy approaches. SME policy is solely based on the size of the firm, whereas entrepreneurship policy is more narrowly defined, focusing more on individuals. 
Entrepreneurship policy refers specifically to attempts to stimulate the creation of new businesses as well as growth within existing organisations. In this case, the question of what constitutes entrepreneurship policy is answered through a list of the types of policy interventions that are likely to promote and support it. These include:

- The promotion of an entrepreneurship culture and more favourable attitudes towards entrepreneurship;

- The integration of entrepreneurship education in schools and at all levels of post-secondary education;

- A reduction in the barriers to entry and re-entry, combined with pro-active measures to make it easier for enterprises to enter the market;

- The provision of seed finance to facilitate business creation and subsequent development;

- The various types of start-up business support including mentoring programmes and business incubators, designed essentially to increase the number of new businesses and nurture their early development;

- Tailored effects to increase the participation in business ownership of under-represented groups, such as ethnic minorities, women and young people.

Although public policy might seem easier to define, what policy means and what processes need to be undertaken in order to apply that policy is not the same in all countries. In China, for example, recognition of the legal existence of small businesses began back in the 1970s with Deng Xiaoping announcing the willingness of the Communist Party to tolerate small businesses employing less than seven people. This was not the result of an explicit policy launch but rather was referred to in the speeches of leading members of the Communist Party, which were interpreted and implemented by local officials.

Even more difficult to define is the term 'policy maker'. In much academic writing the term is used rather too freely because there are relatively few genuine policy makers, for instance government ministers and senior civil servants. In practice, it is suggested that policy-related researchers need to distinguish more consistently between policy making and policy implementation. If making policy recommendations is an objective for a researcher, then it is important to distinguish between policy makers and practitioners. 


\section{Setting the agenda for public policy and policy-related research}

Clearly, the agenda for public policy makers will, to a considerable extent, influence the focus of policy-related researchers. At the same time, the two do not completely overlap because there will always be some 'blue sky' research that may have a major impact on policy making. A good example is the work of David Birch, who drew attention to the fact that the vast majority of employment gains in the US economy came from enterprises employing fewer than 20 people.

The need to place more explicit attention on the role of context is a consistent theme throughout this chapter and research agenda. Indeed, the book itself was stimulated by the work of Welter and others in relation to context. Context refers to the historical, social, economic and, particularly, institutional environment and the interrelationship between them (Welter, 2011). Just as context is important for the study of entrepreneurship, it is also important for the study of entrepreneurship policy. This is because the needs, strengths and weaknesses with respect to opportunities facing countries, regions and/ or localities are variable, as are the possibilities of entrepreneurs to influence and change their contexts. As a consequence, the context in which entrepreneurship can take place varies considerably. For example, Xheneti's chapter demonstrates that context is a salient issue where policy transfer is involved.

To take another example, attempts to transfer policy from European countries to China have proven to be particularly difficult. This is not surprising because of the substantial differences between the cultures in terms of their institutional frames and historical legacies. The influence of contextualisation is well illustrated by an attempt to introduce an effective subsidised consultancy scheme at a local level in China. This is along the lines of a subsidised consultancy scheme managed by the European Bank for Reconstruction and Development (EBRD) in the former socialist countries in Central and Eastern Europe. The scheme is targeted at small businesses that had not previously used external consultants. The idea is that if the public sector subsidises the first round of consultancy use, and if the consultants delivering the advice and support are vetted and accredited, then there should be a double benefit. On the one hand, the market for consulting by small businesses is widened and, on the other, there is an increase in the number of consultants who have experience of working with small businesses. 
Clearly, therefore, the percentage of the total consultancy costs subsidised is central to the question of the extent to which the measure incentivises business owners to make use of consultants. However, in China, the financial support from central government for a policy such as this is only forthcoming when there are some results. In other words, the financial support is retrospective. Clearly, this represents a very different philosophy and is problematic in the case of subsidised consultancy because, in the Chinese model, potential participating businesses do not know what the level of subsidy will be when they are expected to commit to the programme. This uncertainty makes it difficult to recruit small businesses for the programme. Clearly, in this example context matters because of a fundamental difference in the role and mode of operation of key institutions in China compared with countries where the subsidised consultancy model has been successfully applied. This includes a very different relationship between the Central Finance Ministry and the provinces and local cities. The method of dispersing funds in China is considered more of a reward than an incentive. This is an important point to keep in mind when making comparisons where transfer has been made between the two different contexts; and at the same time it opens up future avenues for comparative research on entrepreneurship policy.

A more process-orientated approach by researchers has already been started, with significant inputs from Arshed, some of which is referred to in her chapter with Drummond within this book. The study of public policy typically segregates the policy processes into a number of components. These have been described as, firstly, agenda setting, which refers to the awareness of the priority given to a particular issue; secondly, policy formulation, which refers to the methods used to develop policy options and strategies; thirdly, policy implementation, which refers to the forms and nature of public policy administration and the activities associated with it; and, fourthly, evaluation of policy. Arguably, research can have a role in each of these four stages. In addition, at the policy formulation stage there needs to be some attempt to canvas the views and experience of entrepreneurs and other stakeholders including researchers; to test potentially new policy measures in the way that market research would be used by a private company to assess the market potential of new products, and possibly to fine-tune the measure, including an attempt to identify any unforeseen consequences.

A third item to be added to the public policy agenda is policy monitoring and evaluation. This is not a new topic by any means, and it is true that a number of mature market economies have made a commitment to make more use of evaluation methods. However, still too often evaluation is simply equated with monitoring programme implementation in a very basic form; ex ante 
evaluations are lacking not least because of the efforts this requires to reach out to potential stakeholders and those affected by entrepreneurship policies. This needs to become more widespread, which would generate quite a lot of work with regard to training, for example, on evaluation methods as well as on the best ways to integrate feedback. However, this is what needs to be done because society will want to know what is being achieved with the money that is being spent.

Evaluations, both ex ante and expost, will also help policy makers to recognise the unforeseen consequences that often occur in public policy. There are examples where policy measures trying to achieve what they set out to achieve are actually making the situation worse. In the example of maternity leave legislation for women, if one asks business owners who employ four or five people how they deal with this problem, nine times out of ten they will answer 'I do not employ women of childbearing age'. Clearly, this is discriminatory and not acceptable. Firm size is important here because if a business has a small number of staff, say three or four over a 12-month period, it would find it very difficult to cover their positions, specifically if the staff on maternity leave are specialised.

Despite the evaluation framework promoted by the Organisation for Economic Co-operation and Development (OECD) back in 2007 (OECD, 2007), the number of countries that have systematically applied this type of procedure has been very limited. By and large, policy evaluation is not given the attention that it warrants. This can be supported by the need for transparency in public policy terms and the need to justify the costs involved (the costs in relation to the benefits), but also because effective monitoring and evaluation can feed back into more successful policy development. The framework promoted by the OECD established certain principles justifying more robust policy evaluation, and contained guidance with respect to specific techniques that need to be employed.

A strong policy message which emerges from this review is that the absence of robust evaluation makes it impossible to know the real impact of a scheme in practice. This is a lesson one might suggest for all countries. Arguably, the key lesson emerging from Storey and Potter's chapter is that by not undertaking effective evaluation there could be an opportunity cost. The authors themselves pull out two key priorities. The first is for relevant government ministries charged with entrepreneurship policy to create an evaluation framework that can be applied across a range of policies. The second is to ensure access to data for evaluation, which is typically not included as part of programme 
requirements and therefore not always implemented, particularly in countries where the delivery of policy programmes is contracted out.

In recent years, there has been a growing tendency for policy makers to emphasise the role of evidence in policy formulation. In the UK at least, suitable evidence is limited despite the rhetoric that is often applied in this area. In addition, it may be argued that fundamentally this reflects the fact that enterprise policy is based more on a political rationale than an economic one. Hence, it may be suggested that one of the future policy priorities for both researchers and practitioners is that more explicit attention needs to be paid to the policy process. All we find is that economists working within the developing world have in many respects made more progress in this regard than those focused on domestic policy issues. For example, Young and Quinn's (2002) conceptualisation of the policy cycle demonstrates that research has the potential to influence the process at any stage, whilst the nature of the research may vary.

Another important issue which applies to both entrepreneurship policy and SME policy is that, whilst these terms imply interventions that are focused on the respective target group (whether this be entrepreneurs or SMEs), in practice SME and/or entrepreneurship policy may only affect a small number of people or businesses. In many ways a more useful concept could include the effects of all government policies and actions where they impact on entrepreneurship, although this is not necessarily the aim of the policy makers. The unintended consequences of policy constitutes an important theme for researchers to keep in mind for our future research agenda. Examples include the impact of government laws and regulation, particularly the unintended consequences for small businesses who, unlike a large firm, are unlikely to have specialists, for example in health and safety or for dealing with any kind of bureaucracy.

In other words, we want to put forward that we need to have a broad view on what constitutes policy, in particular entrepreneurship policy. Too frequently still, governments focus narrowly on supporting start-ups and SMEs and neglect the impact that other policy areas will have on entrepreneurship in general. A good example of this is provided by the draft industrial strategy presented by the German Federal Ministry of Economics and Energy in early 2019. This strategy underestimated the impact that the most commonly suggested measures it contained would have on Germany's manufacturing SMEs. The strategy focused on the promotion of large firms, whilst the recently passed Small Business Strategy from the same ministry clearly positioned SME and entrepreneurship policies as a priority policy area. The (initial - in 
the meantime the industrial strategy has been revised) contradiction between these two policies from the same ministry emphasises the need for a holistic approach based on a broad view of what constitutes policies to influence entrepreneurship and small business development.

The justification for taking a broad view is also illustrated in Ndemo's chapter, which focuses on the role of mobile communication technology in the development of entrepreneurship and small businesses in Sub Saharan Africa. Such a measure involving the diffusion of mobile innovation technology would not conventionally be included within the concept of entrepreneurship policy, but clearly the impact of this action, which represents a partnership between the public and private sectors, has had a considerable impact on the development of entrepreneurship in this region. This chapter, together with the chapter by Rogut and Piasecki, also demonstrates the close relationship between entrepreneurship policy and innovation policy in practice. The key point emphasised by Ndemo is the importance of an inclusive innovation policy, as far as both social inclusion and economic development are concerned.

Arguments against entrepreneurship policy have tended to focus on demonstrations of the inadequacies of entrepreneurship policy rather than necessarily the concept itself. These inadequacies highlight, but are not exclusive to, delivery issues. These include a common complaint that many small business owners do not know about, or do not understand, the variety of public policy support available to them, which is often very fragmented and sometimes introduced for short-term political reasons rather than economic argument. Whilst clearly these delivery issues are important since they can have a significant impact on the extent to which a policy is effective, other authors make a more fundamental critique of enterprise policy. The chapter by Arshed and Drummond, for example, makes a critique of enterprise policy in the UK, as does Robert Bennett (2008), who argues that even if market failure could have been demonstrated 20 years ago, most of those market failures have now been eliminated. Indeed, some have argued in this regard that enterprise policy is a waste of taxpayers' money, in that it generally encourages those who are already set on becoming entrepreneurs.

At the same time, implementing studies on the policy process presents a number of challenges. Arshed, for example, negotiated an internship within the ministry responsible for SMEs and entrepreneurship in the UK. Although Arshed was able to sit in on most of the key meetings, she was typically not able to join the meetings when a minister was present. As a result, the role of government ministers in the process is difficult to identify, and yet clearly in terms of the result the minister's influence is likely to be very important. Another 
point that needs to be recognised, once more, is the importance of context, which means that whilst the approach adopted by Arshed is potentially applicable elsewhere, the context may not be. Even within a single country, changes in government over time may well have some impact on the process, as well as, of course, the ruling party and their respective ideologies. Internationally, of course, one might suggest that differences in the background, knowledge and ability of government ministers is likely to show some variation.

At the same time, all the chapters in this volume contain lessons that are potentially of wider application outside of the country in which they have been developed. For example, Smallbone and Do's chapter on policy for internationalising SMEs demonstrates the political nature of entrepreneurship policy, which in this case involves the relationship between the European Union (EU) and national governments. This is reflected in the events leading up to the establishment of the EU's SME Centre in Beijing, and is also reflected in the failure of EU policies to help fill the gap in the case of smaller countries and those perhaps with much less experience of policies to support internationalisation. This chapter also demonstrates the need for rules and frameworks to lay down what is acceptable and not acceptable in terms of the role of internationalisation support programmes in supporting the competitiveness of national businesses.

Not surprisingly perhaps, the key theme emerging from the chapters is, yet again, the importance of placing entrepreneurship policy into context. This argument has been developed strongly with respect to entrepreneurship, but it can be argued that its role also applies very much to the policy arena. Clearly, a good example of this is townships in South Africa where, until 20 years ago, those living there were barred from business ownership. As a consequence, there are likely to be cultural barriers that will affect the current and future development of entrepreneurship. The main challenge for policy makers is to take steps to include social groups in a society based on independence and individualism in townships where a more collective approach is necessary. The main challenge for researchers is to recognise that contextualising entrepreneurship policy is not simply about studying entrepreneurship in townships, but it is about understanding the historical, political and societal contexts that possibly explain why entrepreneurship in townships may be different from what one would expect.

The book also contains cases of countries that only 25 years ago were operating under socialism and central planning, Poland being one example and Russia another. Although Poland and Russia share some common heritage, the two are quite different with respect to encouraging entrepreneurship development. 
Another example emphasising that the nature of context for entrepreneurship and entrepreneurship policy needs to be considered is China, where individuals and institutional frames have changed enormously over the last decades. China shares some common characteristics with the former Soviet republics, but at the same time there are substantial differences, the main one being the ongoing control of society and the economy by the Chinese Communist Party. Whilst in both Russia and China bribery and corruption is rife, bribing the local officials in China to give permission for a particular development to take place may offer double benefits to the official, in that they will receive the bribe but they will also almost certainly be encouraged by local government to continue to implement the development.

Another issue emerging from a number of the chapters in the volume concerns the most appropriate level on which to focus public policy. Smallbone, Li and Xu's chapter on China, for example, demonstrates the importance of a strong policy presence at a sub-national level. The sheer size of China makes it necessary for policy to be sensitive to the spatial variations within the country. This is required because in a country as large as China, the nature and extent of SME support needs will almost certainly vary across territories. This aspect is taken care of by the current approaches of the Chinese government, which emphasises the need for interventions to be compatible with provincial- and city-level interventions. Within Russia, however, where the size of the country is also huge, the state has been very slow to recognise this aspect.

Another country example where the context is very specific for policy makers is Poland. The underlying issue here is the short-term nature of the opportunities for acquiring substantial development and restructuring funds from the EU, as well as the challenges involved in securing these funds. In the medium and longer term this is a danger because it is likely that the short-term emphasis on acquiring such resources has been to maximise the funds received from the EU, which may weaken some of the Central and Eastern European countries in the longer term. There is a danger that at the end of this funding period, when the money is either stopped or severely cut, public policy makers will not be in the position to identify what is required and design appropriate policy responses. 


\section{Future agenda on entrepreneurship policy for researchers and policy makers}

We now turn to setting out a future agenda, differentiating between the research agenda for entrepreneurship policy researchers and that for policy makers.

\section{Entrepreneurship policy researchers}

- More attention needs to be paid to the definition of policy makers, with a clear distinction being made between policy making and policy implementation. This will enable recommendations to be more specifically targeted, distinguishing between policy makers and practitioners.

- Entrepreneurship policy researchers should stress the importance of contextualisation, which can vary between countries, of course, but also between regions.

- Entrepreneurship policy researchers should put more emphasis on the study of policy-making processes, which until recently has not been a major agenda item. This should involve, firstly, agenda setting; secondly, policy formulation; thirdly, policy implementation; and, fourthly, policy evaluation. Amongst other things this would help to narrow the gap between what public policy makers really need and what the universities and business schools are producing.

- Entrepreneurship policy researchers need to critically analyse the policy process, starting with the failure in most cases to undertake any kind of market research concerning the needs of businesses, the needs of regions and the needs of national economies.

- Entrepreneurship policy researchers should seek to address each of the four stages of the policy process. Absence of robust evaluation in many countries is a constraint on improving the quality and effectiveness of entrepreneurship policy. Policy measures focused on entrepreneurship are only likely to impact on a minority of a country's businesses. Researchers also must recognise that the effect of government policies on entrepreneurship and SME development goes beyond policy measures that are specifically targeted at these groups.

- Policy researchers have an important role in stressing the importance of context. When public policies are being designed or analysed, contextual differences, particularly with respect to the institutional framework, can have significant effects on the success of policy measures and programmes.

- Policy researchers have an opportunity to develop more robust concepts of entrepreneurship policy in order to increase their impact on policy making. 
- If researchers are interested in strengthening their role in relation to public policy, they need to engage with policy makers in order to understand the policy process.

\section{Entrepreneurship policy makers}

- Policy makers should place more emphasis on context than is currently given, particularly where policy transfer is involved. Differences between regions and countries can affect the extent to which policies that are transferred are successful.

- Entrepreneurship policy makers and researchers need to take steps to narrow the gap between what public policy makers need and what the business schools and higher education institutions are producing in terms of research.

- Policy makers need to prioritise monitoring and evaluation, setting aside funding for the completion of this at the outset of new measures, and making sure that the appropriate data is collected in order to provide a baseline.

- If policy makers are genuinely interested in evidence-based policy, then research has a role in each of the four stages of policy making identified above.

- Policy makers should recognise the importance of monitoring and evaluation. This should involve including a budget for evaluation at the time a new measure is launched, as well as ensuring that baseline data is gathered during the life of the policy in order to provide a basis for robust evaluation. This may not be easy to achieve if the policy measure was inspired by political gain rather than wider social and economic benefits. Unfortunately, policy making is rarely a logical process, although researchers wish it were so.

- Policy makers interested in strengthening the evidence base for effective policy should be willing to engage with researchers as well as commissioning them to bid for research projects.

- Policy makers need to recognise the unforeseen consequences that often occur in public policy. The frequency of this could be reduced if policy makers made a more significant attempt to market test new policy measures before they are formally launched. In addition, researchers often have the knowledge and experience of SME support needs that policy makers might more systematically draw upon.

In terms of the future policy agenda, this chapter firstly seeks to identify what policy researchers need to take steps to address the needs of policy makers, 
communicated in the form that is likely to have the most impact. This is crucial if the role of academic research in policy making is to be increased. Alan Gibb (2000) identifies a number of what he calls 'myths' which are not helpful in policy making. Gibb's main argument is that many academics and business schools have not served the broadly defined business community well. On the other hand, Perren and Jennings (2005) question the lack of critical perspectives on public policy. This is a position which Xheneti, in her chapter within this volume, addresses in the context of a more critical approach to policy development. On the basis that the future policy agenda and future research in this field needs to be based on a critical view of entrepreneurship policy as it stands, the key arguments presented by Gibb justify further attention. Choosing one of Gibb's hobby horses as an example, we focus on the so-called myth that growth companies are the major job generators. In this regard, Gibb is not alone in his criticism, one aspect of which is the fact that the growth path of an individual firm may look very different depending on the precise years taken for comparison, on the basis that the future agenda for entrepreneurship policy will inevitably be shaped by the strengths and weaknesses that may be identified in contemporary approaches. In this regard, researchers have responded to some of Gibb's key concerns by placing more emphasis on the process of policy development. The work of Arshed is illustrative of this approach. Essentially, this work was initiated by Arshed in her PhD thesis, although clearly this has developed much more since then.

\section{The rest of the book}

The rest of the book is divided into two parts. The first part contains four thematic chapters. The first is by Arshed and Drummond and discusses the shortcomings of enterprise policy in the UK, which in a wider international context has often been seen to incorporate good practice. The chapter focuses on the policy process, which is particularly insightful since one of the authors is a former policy maker. This is followed by a critical piece by Xheneti, who applies some of the findings from her previous work on policy transfer to the wider enterprise policy agenda.

One of the most consistent criticisms of entrepreneurship policy is the lack of attention paid to robust evaluation, and it is fair to say that Storey and Potter have done as much as anyone to promote policy evaluation, as well as undertaking it. The chapter describes how policy evaluation is slowly attracting more serious attention. At the same time, the authors stress that to be effective public policy evaluation needs to be based on appropriate data access and use robust 
methods, which in their case means econometrics methods. The authors also point out that effective policy evaluation needs to be based on appropriate data and undertaken independently. Key problems identified include failure by policy designers to make provision for the data to be generated from day one. Another issue is the tendency for policy objectives to be insufficiently and unclearly specified, which almost certainly reflects a situation where policy objectives are more about politics than they are about economy. The final chapter in this part, authored by Smallbone and Do, takes a critical look at policies to support internationalisation. The focus in this chapter is on Europe, and both national- and EU-level policies are included.

The second part of the book contains country-specific perspectives on different aspects of a future research agenda on entrepreneurship policy. In the first chapter in this part, authored by Smallbone, Xiao and $\mathrm{Xu}$, the relationship between national and sub-national policies is examined, which in China, the country that is the focus of this chapter, means the provincial and city level. This chapter utilises new material to demonstrate regional variations in entrepreneurship in China.

This is followed by a chapter on the Russian Federation, written by Barinova, Zemtsov and Smallbone, which has been one of the slowest of the transition economies to develop its SME sector. This is associated with the fact that large enterprises still dominate the Russian economy, but it also reflects the lack of an entrepreneurial spirit, which may be explained by the fact that Russia essentially moved from a feudal structure to a socialist one with no private enterprise experience in between. At the same time, the chapter adopts an upbeat stance, although only time will tell whether the current programme of support for SMEs will be successful.

The next chapter is also on a country, Poland, that for many years operated an essentially planned economy under socialism. However, unlike Russia, entrepreneurship took off very quickly once the reform process was underway. The chapter by Rogut and Piasecki discusses two interrelated issues, the first concerned with how to stimulate more innovation in Poland's SMEs and the second related to the EU as a source of funding for structural change.

The SME sector in Japan is something of a black box for many Western researchers because many of the researchers looking into entrepreneurship in Japan do not have a sufficient command of the English language. In this context, the chapter by Mitsui provides some valuable insights into the reasons for declining entrepreneurship, which clearly is a different message from that which Western researchers are used to hearing. Although very different to the 
preceding chapter on Poland, there is a shared interest in encouraging entrepreneurship that is innovative in nature.

The next chapter on Sub Saharan Africa, written by Ndemo, is particularly interesting for two reasons: firstly, because it demonstrates how entrepreneurship can be affected by a wide range of government policies and actions that are not necessarily targeted at entrepreneurs; and, secondly, because the author spent ten years in government himself, including a period as a government minister. The example in this chapter is the above-mentioned effect of mobile communications technology, which in Sub Saharan Africa is not just viewed as enabling self-employed and small businesses to widen their scope of operation.

The final chapter is concerned with South Africa, which some commentators view as an example of a transition economy with some similar features to those found in Central and Eastern Europe. Instead of a post-socialist context, the context in South Africa is post-apartheid, with a focus on the township. In this chapter Mazwai argues that that the lack of entrepreneurship in the black population has been a very difficult nut to crack, with a series of policy interventions which do not appear to have contributed very much to addressing the needs of entrepreneurs and SMEs. Thus, this chapter is concerned with increasing social inclusion on a very large scale.

\section{References}

Bennett, R. (2008), 'SME policy support in Britain since the 1990s: What have we learnt?', Environment and Planning C: Government and Policy, 26 (2), 375-97.

Gibb, A. (2000), 'SME policy, academic research and the growth of ignorance, mythical concepts, myths, assumptions, rituals and confusions', International Small Business Journal, 18 (3), 13-35.

OECD (2007), OECD Framework for the Evaluation of SME and Entrepreneurship Policies and Programmes, Paris: OECD Publishing.

Perren, L. and P. L. Jennings (2005), 'Government discourses on entrepreneurship: Issues of legitimization, subjugation and power', Entrepreneurship Theory and Practice, 29 (2), 173-84.

Welter, F. (2011), 'Contextualizing entrepreneurship - Conceptual challenges and ways forward', Entrepreneurship Theory and Practice, 35 (1), 165-84.

Young, E. and L. Quinn (2002), Writing Effective Public Policy Papers: A Guide to Policy Advisers in Central and Eastern Europe, Budapest: LGI. 